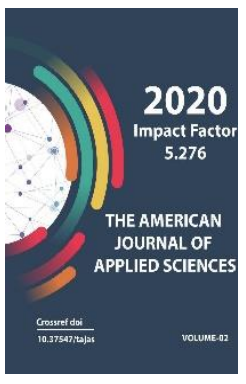

Journal Website: http://usajournalshub.c om/index,php/tajas

Copyright: Original content from this work may be used under the terms of the creative commons attributes 4.0 licence.

\section{Determination Of Tungsten By Solid Phase Spectroscopy Using Immobilized Reagents}

\author{
Rakhimov S.B. \\ National University Of Uzbekistan Named After Mirzo Ulugbek, Tashkent, Uzbekistan \\ Khalilova L.M. \\ Navoi Pedagogical Institute, Navoi, Uzbekistan \\ Zhumaeva E.Sh. \\ Navoi Pedagogical Institute, Navoi, Uzbekistan \\ Gafurova D.A. \\ National University Of Uzbekistan Named After Mirzo Ulugbek, Tashkent, Uzbekistan \\ Smanova Z.A. \\ National University Of Uzbekistan Named After Mirzo Ulugbek, Tashkent, Uzbekistan
}

\title{
ABSTRACT
}

A sorption-spectroscopic technique for the determination of tungsten by immobilized pyrocatechol violet and sodium salt of 1- (2-hydroxy -1-naphtho-azo) -2-naphthol-4-sulfonic acid has been developed. The optimal conditions for the determination of tungsten were selected and the conditions for immobilization on various types of sorbents (SMA-1, SMA-2, PPM-1, PPD-1, PPA-1) were optimized. The subordination of the tungsten complex with immobilized pyrocatechol violet Beer's law was studied. The calibration graph is linear in the concentration range $0.05-2.00 \mu \mathrm{g} / \mathrm{ml}$. Sr does not exceed 9.0 $\cdot 10-$ 2. The proposed technique has been tested on various types of waters.

\section{KEYWORDS}

Immobilization, toxic metals, tungsten, pyrocatechol violet, sodium salt of 1- (2-hydroxy-1-naphthaazo) -2-naphthol-4-sulfonic acid, sorption-spectroscopic determination.

\section{INTRODUCTION}

Analysis the environmental condition and the presence of major problems in the utilization and protection of natural resources are reflected in numerous publications of scientists 
and specialists. One of the main problems is related to the ensuring environmental safety. Because this issue depend on the global threats to environmental safety [1]. Among this types of influences on the environment, the chemical factor should be singled out, as an anthropogenic component which has outstripped the natural one [2]. Control over the content of trace elements in natural objects and industrial materials, which play an important role in various processes, is an important task of analytical chemistry.

According to the currently valid GOST standards for control methods, the determination of trace amounts of toxic metals, in particular Mo, V, W is carried out by volumetric methods [3], which in some cases do not meet the modern requirements for expressiveness, accuracy, sensitivity and detection limit $(\mathrm{Sr}=0,17-0.29$ at $\mathrm{C}=\mathrm{n} \cdot 10-2-\mathrm{n}$ $\cdot 10-4 \%)$.

Tungsten is a natural metal element mainly used for incandescent light bulbs and X-ray tubes. Tungsten is commonly used as a nontoxic alternative to lead in a wide variety of industrial and military applications. Initially, it was believed that tungsten is non-toxic, since it is an inert metal with low mobility [4-6]. However, the correlation between environmental pollution and biological effects led to its classification as "new pollutants". Water in such areas contains high metal concentrations. Experts believe that tungsten has toxic and carcinogenic effects on human health [7].

According to the literature survey [8] high concentrations of tungsten found in urine samples are closely related to the incidence of stroke. The problem is that during the production process, metal enters the environment and with groundwater settles on agricultural land. Water in such areas contains high metal concentrations. Control of the tungsten content in environmental objects is gaining factor. Most of the known methods for its determination, due to insufficient selectivity, do not allow the determination of tungsten in complex objects. In this regard, the importance of rapid, reliable analytical control over the tungsten content in environmental objects becomes obvious.

Currently, there are some types of methods for the photometric determination of tungsten in the form of colored complexes. Reactions with dithiol, ammonium thiocyanate and 8hydroxyquinoline are still used [9-11].

The rhodanide complex for the determination of tungsten, proposed for the first time by Feigl and Krumholtz was constantly being improved and the changes were mainly in the choice of the nature of the reducing agent, the procedure for merging the reagents and the method of reducing tungsten. Feiglem proposed tin dichloride in the presence of hydrochloric acid, then Ferjanich used titanium trichloride, and Gotschek used tin amalgam. The authors [12-13] tested zinc dust and used photochemical reduction with a mercuryquartz lamp.

Extraction-photometric methods have been proposed for the determination of tungsten in the form of molybdenum-tungsten blue [14], thiocyanate using a chloroform solution of alphabenzoinoxime, isoamyl alcohol, isobutanol, isopropyl ether as an extractant. The spectrophotometric method has been proposed to determine tungsten with ferrocyanide in hydrochloric acid solution [15]. Stolyarov proposed perfect method for the determination of tungsten using oxyquinoline, 
the interfering effect of a number of foreign metals is prevented by the addition of a complexone Sh. Vanadium is preliminarily reduced with ascorbic acid. The extraction of tungsten is carried out with a chloroform solution. Lead, cadmium, arsenic and no more than 50-fold amounts of zinc, silver and chromium do not interfere with the determination, molybdenum and iron interfere. It is recommended to preliminary separate them by extraction with diethyl ether: from hydrochloric acid medium. The extracts obey Beer's law well up to a tungsten concentration of $100 \mu \mathrm{g} / \mathrm{ml}$. The developed technique was tested on many samples of steels and ores [16].

In the spectrophotometric determination of tungsten, ORs have been proposed and widely used as ORs: hydroxyl-containing (hydroquinone, pyrocatechol, phenylfluorone, chromotropic acids, tiron, alizarin), triphenylmethane dyes (pyrocatechol violet), trioxyfluorones, nitrogen- and sulfurcontaining and their derivatives. The disadvantage of these methods is the nonselectivity of the determination of tungsten, which is interfered by the accompanying metals [17-18].

The complex chemical, mineralogical and granulometric composition of tailings, sludge, a set of contained rock-forming minerals pose the task of increasing the yield of tungsten during additional extraction [19-22]. There is an acute issue of increasing the production of non-ferrous and rare metals with the use of deeper processing of ores, attraction of reserves of difficult-to-process rocks, tailings and slag accumulated in dumps and tailing dumps, as well as secondary raw materials into processing. At the same time, the need for the use of man-made waste in our country has recently been due to the convergence of their quality with the quality of natural raw materials. This is especially true for stale waste that has accumulated since the years when rich ores were developed, and their processing was accompanied by large losses of metals [22-29]. Many methods have been proposed for the determination of ores, where tungsten is present as an accompanying interfering metal [30-31].

The use of immobilized organic reagents of a number of catecholics makes it possible to determine almost all metal ions, including tungsten ions. This makes it possible to develop more selective methods for the determination of many metals and to increase the detection sensitivity.

The aim of this research is to develop new and improve existing sorption-spectroscopic methods for the determination of tungsten.

Previously, it was found that for the immobilization of polyoxyflavones the best results are shown by polyacrylonitrile type sorbents SMA, therefore the choice of the best carrier was carried out among sorbents of this type [32-33].

\section{MATERIALS AND METHODS}

A solution of tungsten with an approximate concentration of $1 \mathrm{mg} / \mathrm{ml}$ was prepared by dissolving a weighed portion of $\mathrm{Na}_{2} \mathrm{WO}_{3} \cdot \mathrm{H}_{2} \mathrm{O}$ of chemically pure grade in $0.5 \mathrm{~N} \mathrm{NaOH}$. The titer of the solution was determined gravimetrically by precipitating $\mathrm{WO}_{3}-[34]$. The titer of the resulting solution is $0.8659 \mathrm{mg} / \mathrm{ml}$. Equipment. The $\mathrm{pH}$ of the solutions was measured on a PHS-3E pH meter (China) with a measurement accuracy of 0.0001 units. IR spectrum of the reagent, carrier, and immobilized organic reagent were recorded on 
an Avatar system 360 FT-IR spectrometer (Nikolet Justrument Corporation, USA), as well as on a SPECORD UR-10 instrument (Germany). Electronic absorption spectra of the investigated solutions of reagents and their complex compounds with metal ions were recorded on an SF-46 spectrophotometer and a KFK-3 photoelectrocolorimeter (Russia).

The initial $0.05 \%$ solution of pyrocatechol violet (PF) is prepared by dissolving $50 \mathrm{mg}$ of the drug in $80 \mathrm{ml}$ of ethanol containing $1 \mathrm{ml}$ of $6 \mathrm{M} \mathrm{PF}$ while heating in a water bath; after cooling, the solution is diluted to $100 \mathrm{ml}$ with ethanol. A working solution of $0.005 \%$ by PP, $30 \%$ by ethanol and $0.5 \%$ by $\mathrm{HCl}$ is prepared by mixing $4 \mathrm{ml}$ of the original PP solution, $8 \mathrm{ml}$ of ethanol and $3.3 \mathrm{ml}$ of $6 \mathrm{M} \mathrm{HCl}$ and diluting to $40 \mathrm{ml}$ with water. To create acidity, $0.1 \mathrm{M}$ solutions of $\mathrm{HCl}$ and $\mathrm{NaOH}$ are used [35].

A $0.1 \mathrm{M}$ solution of sodium salt of 1- (2-hydroxy -1-naphtho-azo) -2-naphthol-4-sulfonic acid (GNS) was prepared by dissolving $3.93 \mathrm{~g}$ of the drug in a $100 \mathrm{ml}$ flask.

Polyacrylonitrile fiber modified with hexamethylenediamine is used as a solid phase. From this material, 0.2-0.3 mg of carrier is weighed. The carriers are washed with $0.1 \mathrm{M}$ $\mathrm{HCl}$ solution and then with water until neutral medium, stored in Petri dishes in a wet state.

Method for determining tungsten: variable amounts of metal are poured into a $25 \mathrm{ml}$ flask from $0.5 \mathrm{ml}$ of solution ( $\mathrm{CW}=50 \mu \mathrm{g} / \mathrm{ml}$ ), $0.5 \mathrm{ml}$ of $0.2 \mathrm{M}$ hydrochloric (sulfuric) acid solution, distilled water is added to the mark, stirred and is passed through a carrier previously kept in 4 $\mathrm{ml}$ of a $10 \%$ solution of the PF reagent.

The analyzed solutions with a volume of 10-100 $\mathrm{ml}$ are passed through the carriers, which were immobilized with an organic reagent, at a rate of $10 \mathrm{ml} / \mathrm{min}$. The reflection spectra are recorded on the X-Rite Eye-One Prominispectrophotometer "gretagmacbeth", the absorption spectra on the spectrophotometer "EMC-30PC-UV".

The analytical signal is the difference in the diffuse reflectance coefficients of the carriers after passing the control and the analyzed solutions. The control solution contains all the components of the reaction, except for tungsten ions and goes through all the operations as the test solution.

\section{RESULTS AND DISCUSSIONS}

The complexation of tungsten with various organic oxyreagents was studied: pyrocatechol (PC), pyrocatechol violet (PP), phenylfluorone (PF), and sodium salt of 1- (2hydroxy -1-naphtho-azo) -2-naphthol-4-sulfonic acids (GNNS) through reflection spectroscopy (Table 1). Based on the difference in reflection coefficients, it was found that the reagent pyrocatechol violet (PF) and sodium salt of 1(2-hydroxy -1-naphtha-azo) -2-naphthol-4sulfonic acid (GNNS) give a positive effect (Table 1).

Table 1

Diffuse reflectance difference $(\Delta \mathrm{R})$

\begin{tabular}{|c|c|c|c|c|}
\hline Reagent & PF & FF & GNNS & PK \\
\hline$\Delta R$ & 0,87 & 0,69 & 0,92 & 0,55 \\
\hline
\end{tabular}


Complexation in the metal-immobilized reagent system was studied by plotting curves: the intensity of absorption or reflection - $\mathrm{pH}$, the composition of the buffer mixture, the metal content, the concentration of the organic reagent, the order of draining and the time.

Table 2

Dependence of the degree of sorption (\%) on the acidity of the medium

\begin{tabular}{|c|c|c|c|c|c|}
\hline \multirow{2}{*}{$\begin{array}{c}\text { Terms } \\
\mathrm{pH}\end{array}$} & \multicolumn{5}{|c|}{ Polyacrylonitrile base } \\
\cline { 2 - 6 } & SMA-1 & SMA-2 & SMA-3 & PPD-1 & PPA-1 \\
\hline 5 & 2,4 & 10,2 & 3,9 & 16,5 & 7,3 \\
\hline 7 & 1,2 & 8,5 & 2,6 & 15,3 & 5,4 \\
\hline 9 & 2,7 & 9,8 & 4,2 & 15,9 & 6,8 \\
\hline
\end{tabular}

The high degree of reagent retention (80 98\%), observed on the PPD-1 sorbent, is apparently due to the fact that the largest number of anion-exchange groups is located on this carrier.

Table 3.

Spectrophotometric characteristics of tungsten complexes with GNNS and PP solution and immobilized on a polymer carrier

\begin{tabular}{|c|c|c|c|c|}
\hline \multirow{2}{*}{ Metal ion } & \multicolumn{2}{|c|}{ Optimal acidity, $\mathrm{C}\left(\mathrm{H}_{2} \mathrm{SO}_{4}\right)}$, & \multicolumn{2}{c|}{ Wavelength, $\mathrm{nm}$} \\
\cline { 2 - 5 } & pH in solution & on the matrix & in solution & on the matrix \\
\hline GNNS- W(VI) & 1,0 & 0,05 & 480,570 & 540,580 \\
\hline PF-W(VI) & $2-3$ & 0,5 & 500,530 & 540,560 \\
\hline
\end{tabular}

Polyacrylonitrile fibers modified with various anion-exchange groups are characterized by a large active surface and, therefore, a high sorption capacity (Fig. 1-2). 


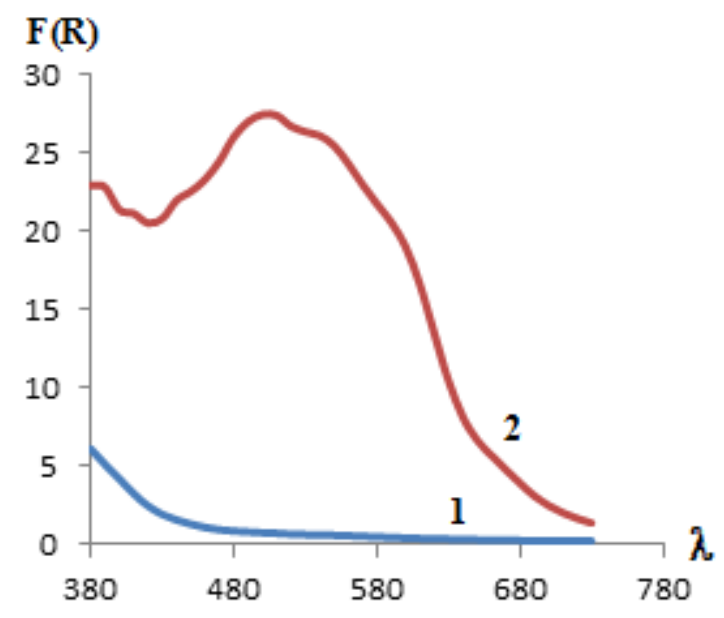

Fig. 1. Reflectance spectra of the PPD sorbent (1) and the GNNS reagent immobilized on the carrier (2).

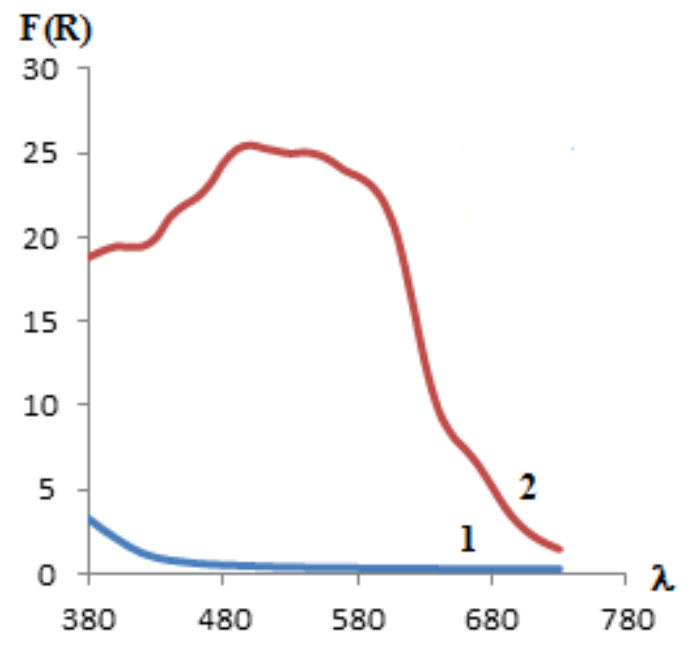

Fig. 2. Reflection spectra of the SMA sorbent (1) and the PF reagent immobilized on the support (2).

When passing from an acidic to an alkaline medium, the degree of retention of the reagents on the sorbent drops sharply (Fig. 3), which is associated with the dissociation of the hydroxy groups of the reagents, which acquire a negative charge and are repelled from the negatively charged polymer surface. 


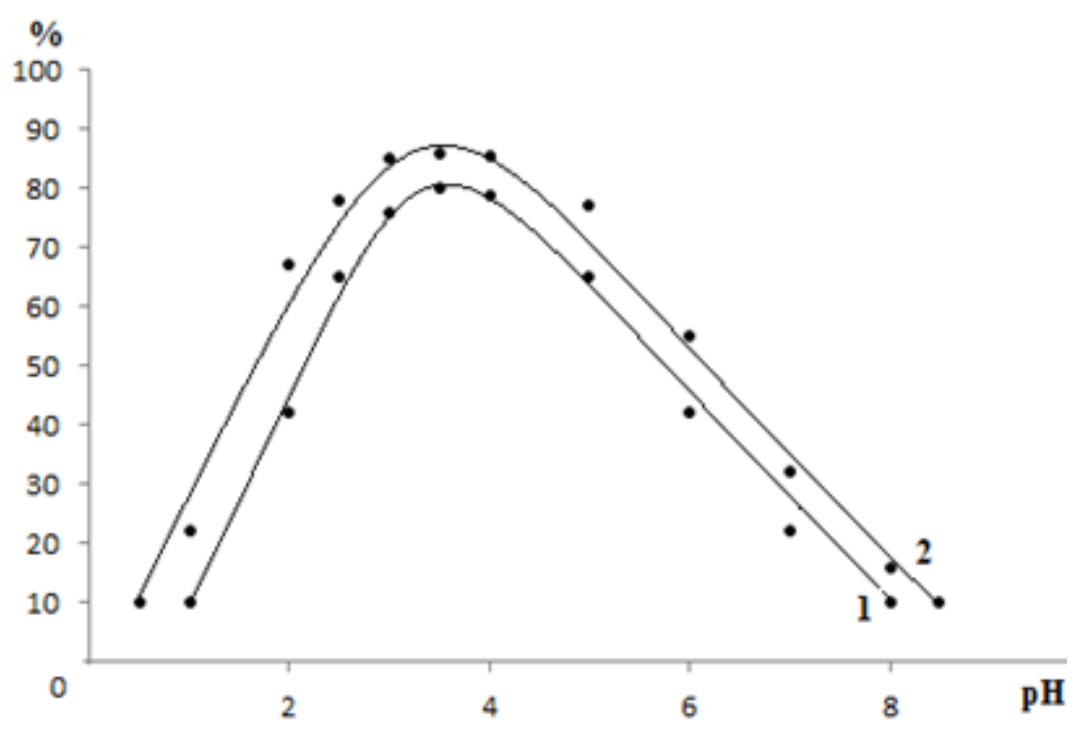

Fig 3. Dependence of the degree of PF sorption on the polymer sorbent SMA-1 (1) and PPD-1 (2) on the acidity of solutions.

The dependence of the degree of PP sorption on a polymer sorbent on the acidity of solutions on various types of sorbents showed that the matrix modified with HMDA is characterized by a higher degree of sorption of the reagent (90 - 95\%) (Fig. 3, curve 2) than for other fibers modified with HA (Fig. 3, curve 1). This is due to the weakening of bonds between randomly located macromolecules, as a result of which the sorption capacity of the fiber increases. The presence of a sulfo group in reagents, in which positive charges are formed during the redistribution of the electron bond density on the sulfur atom, which leads to a stronger interaction of reagent molecules with the active centers of ordered fiber macromolecules located closer to the surface, making it difficult for the reagent molecules to penetrate deep into the fiber. The access of the solvent to the surface adsorption centers, with the reagent molecules attached to them, is much easier, which leads to the washing out of the PP.

In fig. 4 shows the isotherms of sorption of PF and GNNS on polymer matrices. PF isotherms belong to the S-type and characterize nonchemical types of adsorption due to dispersion forces, hydrogen bonds or hydrophobic interactions. GNNS isotherms belong to the Ltype and characterize chemical interactions due to ion exchange and intermolecular hydrogen bonds. Such a curve is observed with extremely strong adsorption at very low concentrations; they intersect with the ordinate axis [36]. 


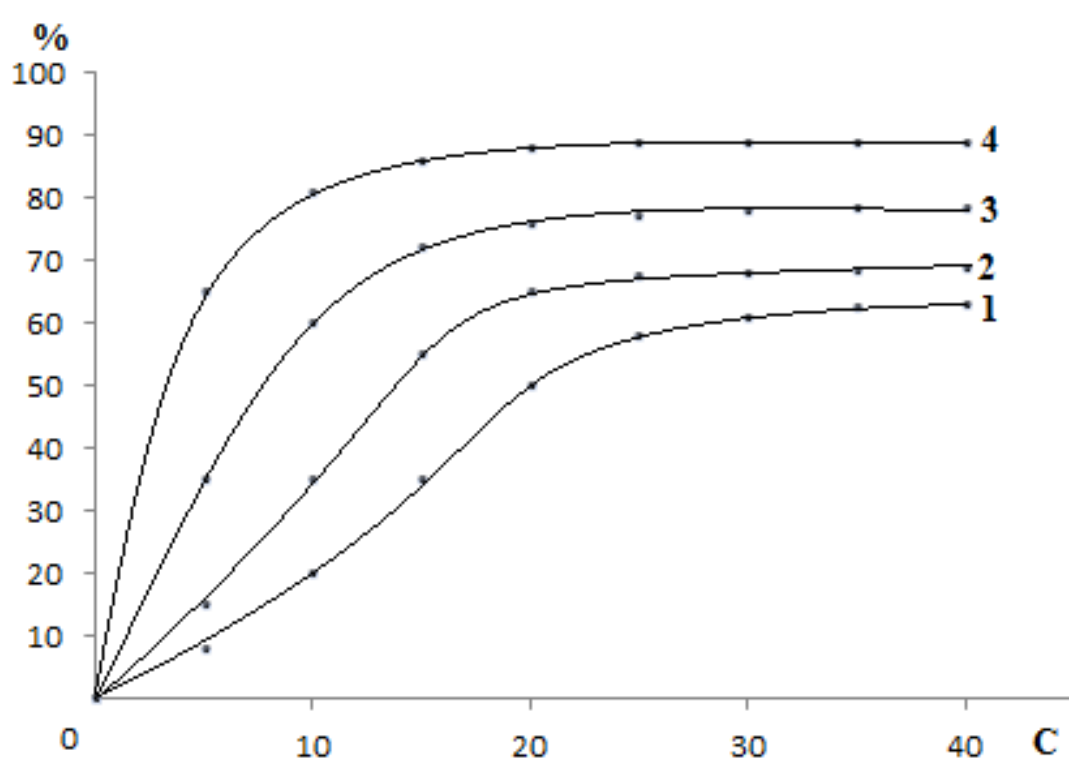

Figure: 4. Isotherms of PF sorption on SMA-1 (1), SMA-2 (2) and GNNS on SMA-1 (3)

$$
\text { and PPD -1 (4) at } \mathrm{pH}<5 .
$$

The plateaus on the sorption isotherms of the PF and GNNS reagents reflect the completion of the formation of the monomolecular coating of the support. Based on the type of experimental sorption isotherms, it can be assumed that PP and GNNS molecules are retained on the surface of polymeric fibrous carriers, due to chemical bonding ( $\mathrm{HC}_{1}$, displaced during the interaction of the carrier with a reagent from an aqueous medium) and other bonds (hydrogen, Van der Waals forces and etc.).

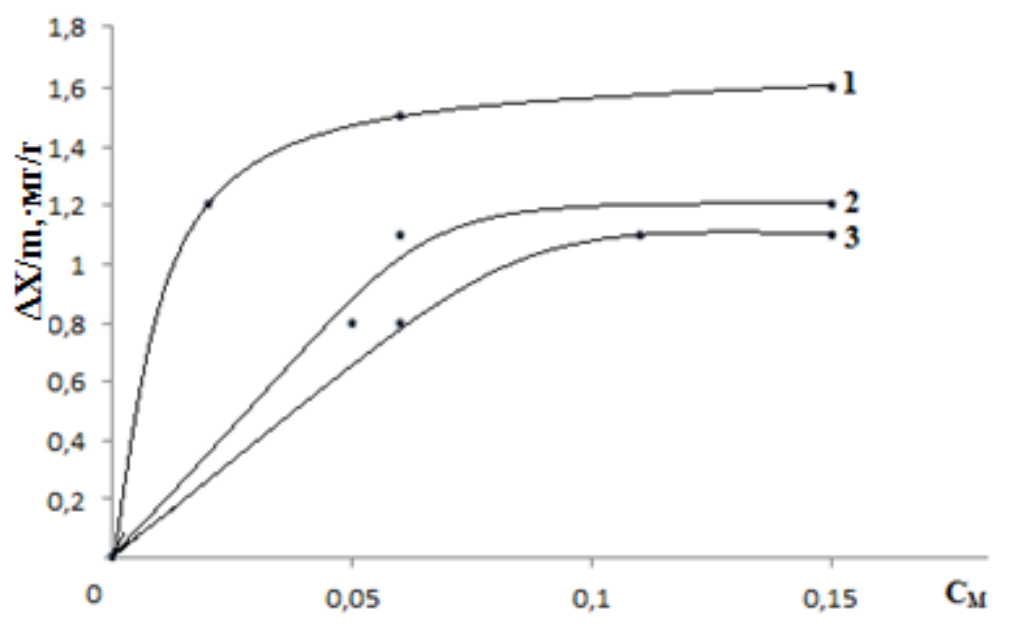

Fig. 5: The isotherm of sorption of GNNS on PPD-1 (1), SMA-1 (2) and PPA-1 (3) at pH $<5$.

From the point of view of the analyst chemist, stability plays an important role in the preparation of the complex, since over time the stability of the complex can affect the 
stability of the optical density measurements.

The measurement results are shown in Figure

6.

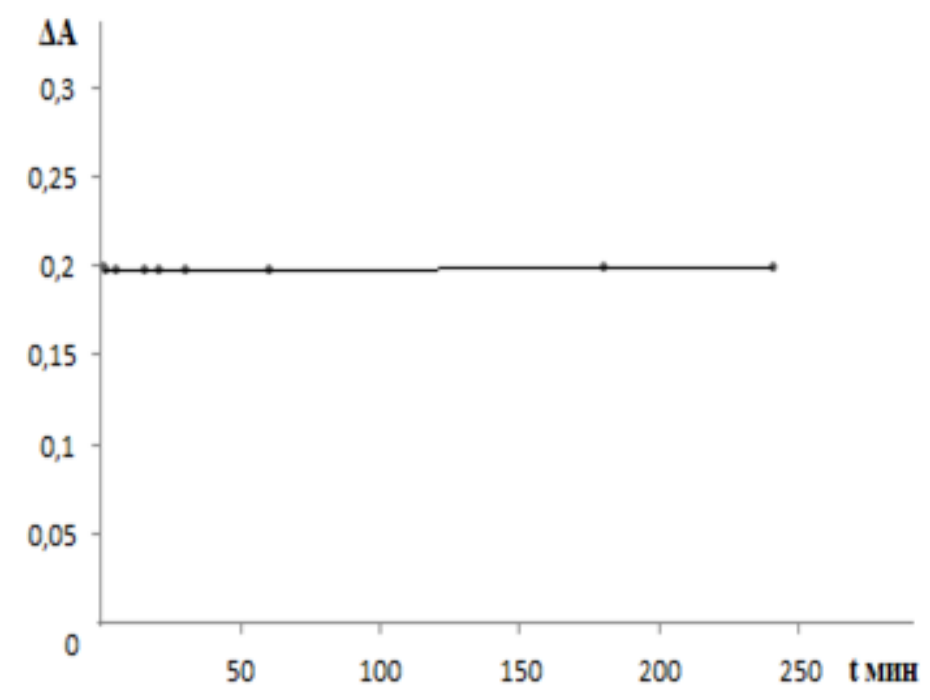

Figure: 6 . Study of the time dependence of the complexation

The study of the time dependence of the complexation process showed that the maximum optical density of the complex is established immediately after the addition of the reagents and it has not changed for a long time.

The subordination of the investigated complex of tungsten with immobilized pyrocatechol violet Beer's law was verified.

The experiments were carried out according to the following procedure: a variable amount of a tungsten solution with a titer of $0.1 \mathrm{mg} / \mathrm{ml}, 2$ $\mathrm{ml}$ of a hydrochloric acid solution were sequentially put into $25 \mathrm{ml}$ flask and the volume was brought to the mark with bidistilled water and passed through an immobilized PF carrier. The reflection spectra of the carrier were recorded before and after the passage of the metal solution (Fig. 7). Figure 7 shows that the complex obeys Beer's law in the concentration range from 2.5 to 100 $\mu \mathrm{g}$ in $50 \mathrm{ml}$ of solution.

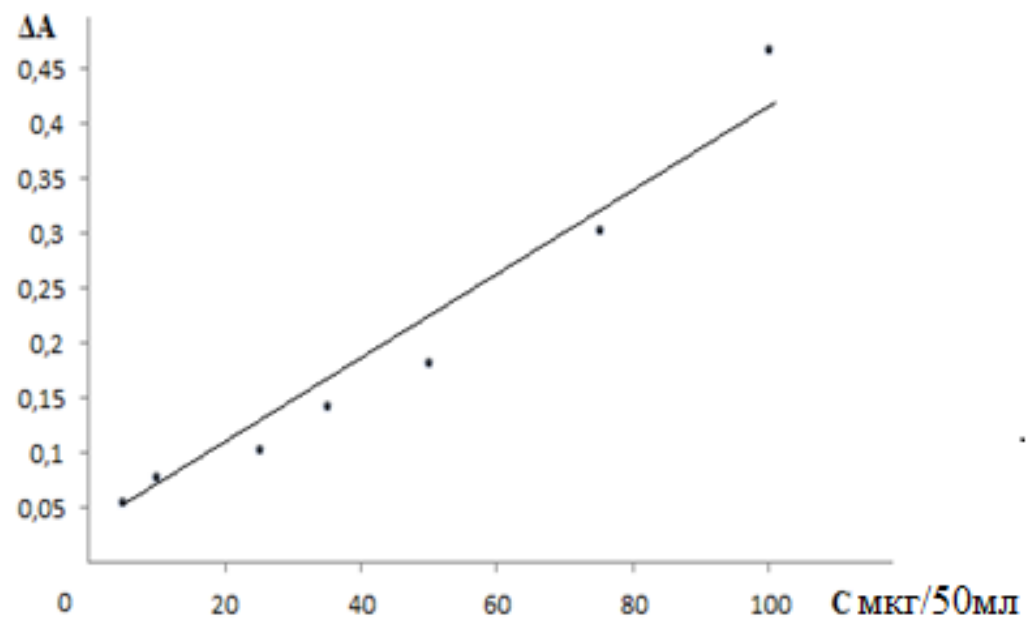


Figure: 7. Calibration graph of dependence

The graph of the dependence of the diffuse reflection coefficient on the concentration of tungsten $(\mathrm{VI})$ ions is linear in the concentration range of $0.05-2.00 \mu \mathrm{g} / \mathrm{ml}$. Sr does not exceed $9.0 \cdot 10-2$.

The sensitivity and selectivity of the reaction of tungsten ( $\mathrm{VI}$ ) with immobilized pyrocatechol violet is rather in comparison to solution (Table 1).

The developed technique was applied by us to determine tungsten in industrial effluents and some types of water $-0.1138+0.0143 \cdot 10-2 \mathrm{~g} / \mathrm{l}$. The relative standard deviation does not exceed 0.019 .

\section{REFERENCES}

1. Davydova S.L. On the toxicity of metal ions // Series "Chemistry" № 3, 1991, p. 243

2. Moore JV, Ramamurti S. Heavy metals in natural waters. M .: Mir, 1987, p. 297.

3. GOST 12.1.005-88 "General sanitary and hygienic requirements for the air in the working area (with amendment № 1)".

4. GOST 12.1.007-76 SSBT. "Harmful substances. classification and general safety requirements (with amendments $\mathrm{n} 1$, 2)".

5. Wise I.V. Heavy metals in the soil - plant human system // Hygiene and Sanitation. Moscow, 1997, № 1, p. 14-16.

6. Salikhodzhaev S.S. Occupational hygiene and clinical and social changes in persons engaged in the extraction, enrichment and use of tungsten and its compounds in conditions // Uzbekistan. Author's abstract. Doc. Dis. M. 1970.
7. Filyard, Semyonova E.I. Properties of rare elements // Reference. M: Metallurgy. 1964.

8. Wise I.V. Heavy metals in the soil - plant human system // Hygiene and Sanitation. Moscow.-1997, № 1, p. 14-16.

9. Perelman F.M., Zvorykin A. Ya. Molybdenum and tungsten // $\mathrm{M}$.: Nauka, 1968, p. 132-139.

10. Perrin D. Organic analytical reagents // Mir, 1967, p. 408

11. Tungsten. Zelikman A. N., Nikitina L. S. M., "Metallurgy", 1978, p. 272.

12. GOST- 14339.1-82. Tungsten determination methods.

13. GOST 12349-83. Alloyed and high-alloyed steels. Methods for the determination of tungsten.

14. Fishman MA, Sobolev DS Practice of concentration of non-ferrous and rare metals ores. T. IV. M., "Nedra", 1963, p. 712.

15. Sinyaeva N.P., Nekrasova L.P., Boguslaev A.V., Klochikhin V.V. Determination of tungsten, molybdenum, vanadium in steels and nickel-based alloys // Standardization and metrology. 2007, p. 8-162.

16. Busev A.I., Ivanov V.M., Sokolova T.A. Analytical chemistry of tungsten // Publishing house of sciences "Moscow" 1976, p. 272

17. Smoldyrev A.E. Possibilities of mining tailing dumps // Mining journal -2002, №7, p. 54-56.

18. Mining sciences. Development and conservation of the Earth's interior // RAS, AGN, RANS, MIA; Ed. K.N. Trubetskoy. - M .: Publishing house of the Academy of Mining Sciences, 1997, p. 478.

19. Bocharov, VA Technology of concentration of gold-containing raw materials // Moscow: Izd. House "Ore and Metals", 2003, p. 407. 
20. Frolova IV, Tikhonov VV, Nalesnik OI, Sokolova AD, Streltsova AA Study of tailings of tungsten ores of the Bom-Gorkhonskoye deposit for washability // Izvestiya vuzov. Chemistry and chemical technology. - 2014, T. 57, № 1, p. 39-41

21. Apeltsin F.R., Getmanskaya T.I., Lisitsyn A.E. Tungsten deposits, criteria for their search and evaluation - M .: Nedra, 1980, p. 250-252.

22. Chuyanov G.G. Tailings ponds of concentration plants // Izvestiya VUZov, Mining Journal - 2001, № 4-5, p. 190-195.

23. Fishman M.A., Sobolev D.S. The practice of dressing ores of non-ferrous and rare metals, vols. 3-4, M: Gosgortekhizdat, 1963.

24. Kvitka VV, Kumakova LB, Yakovleva EP. Processing of stale tailings of dressing of factories of East Kazakhstan // Mining journal (Mining journal) 2001, № 9, p. 57-61

25. Voronin D.V., Havelia E.A., Karpov S.V. Study and processing of technogenic deposits // Ore dressing (processing of minerals) 2000, p. 16-20.

26. Smoldarev A.E. Waste processing methods // Mining journal (Mining journal) 2002, p. 54-56.

27. Kozin V.Z. Study of ores for concentration // Ural. state Gorny un-t - Yekaterinburg: Publishing house of USMU, 2008, p. 10-65.

28. Erik Lassner, Wolf-Dieter Schubert. Tungsten: Properties, Chemistry, Technology of the Element, Alloys, and Chemical Compounds. - Springer Science Business Media, LLC. 1998, p. 183-187.
29. Frolova I. V., Tikhonov V. V., Nalesnik O. I., Streltsova A. A. The Enrichment of Stale Tailings of Bom-gorhon Tungsten Ore Deposits // Procedia Chemistry. - 2014, № 10, p. 364-368.

30. Amelin V.G., Abramenkova O.I. Test determination of molybdenum (VI) using phenylfluorone immobilized on cellulose tissue // Zh. analyte. chemistry. 2007, № 12, T. 62, p. 1316-1318.

31. Salamov A.Kh., Alakaeva L.A. Determination of molybdenum in the presence of tungsten in various objects // Fundamental research. - 2013, № 10-1, p. 86-89.

32. Madusmanova N.K., Smanova Z.A., Zhuraev I.I. Properties of a new analytical reagent 2hydroxy-3-nitrosonephthaldehyde // Journal of Analytical Chemistry, 2020, Volume 75, № 1, p. 92-96

33. Gafurova D.A., Shahidova D.N., Mukhamediev M.G., Mukhamedov G.I. Some features of the interaction of nitrogen-containing bases with polyacrylonitrile // Reports of the Academy of Sciences of the Republic of Uzbekistan. Tashkent, 2013, № 4, p. 40-42.

34. Korostylev P. P. Laboratory technique of chemical analysis // M.: Chemistry, 1981, p. 203-206.

35. Lurie Yu.Yu. Analytical Chemistry Handbook // - $M$.: Chemistry, 2004, p. 480

36. Zolotov Yu.A. Fundamentals of Analytical Chemistry. In 2 kn .. kn. 2. Moscow Publishing Center "Academy", 2012, p 503 